\title{
ESCRITA DISCIPLINAR: CONTRIBUIÇÕES PARA O ENSINO DE LÍNGUA PORTUGUESA NA GRADUAÇÃO
}

\author{
Elizabeth Maria da Silva* \\ Universidade Federal de Campina Grande \\ Campina Grande, Paraíba, BR
}

\author{
Maria Augusta Gonçalves de Macedo Reinaldo ${ }^{* *}$ \\ Universidade Federal de Campina Grande \\ Campina Grande, Paraíba, BR
}

\begin{abstract}
Resumo
Objetivamos neste artigo: (1) descrever uma proposta de ensino de escrita para cursos de graduação orientada pelos princípios teórico-metodológicos que norteiam a abordagem de Escrita nas Disciplinas e (2) identificar e analisar as percepções de graduandos sobre a implementação desse tipo de metodologia de ensino da escrita. Para isso, aplicamos um questionário com estudantes do Curso de Ciência da Computação que cursaram a disciplina Leitura e Produção de Textos (LPT), ofertada para diferentes cursos de graduação de uma universidade pública do interior paraibano. Os depoimentos desses alunos apontam para o reconhecimento de que é necessário ensinar na universidade a escrita acadêmica; de que esse ensino deve ser específico; de que um dos fatores que contribuem para o processo de apropriação dos textos acadêmicos é a prática de escrevê-los; e de que o aluno pode ser um agente da aprendizagem, indicando para o professor de LPT textos específicos da sua área.
\end{abstract}

Palavras-chave: Universidade; Ensino de Escrita Acadêmica; Escrita nas Disciplinas

\section{DISCIPLINARY WRITING: CONTRIBUTIONS TO PORTUGUESE LANGUAGE TEACHING IN UNDERGRADUATE COURSES}

\begin{abstract}
In this paper we aimed at (1) describing a proposal for the teaching of writing in undergraduate courses guided by theoretical and methodological principles that underlie the approach of Writing in the Disciplines and (2) identifying and analyzing undergraduate students' perceptions on the implementation of this type of methodology for teaching writing. For this, we applied a questionnaire to students of Computer Sciences who attended the discipline Reading and Text Production (RTP), offered for different undergraduate courses at a public university in the interior of Paraiba. The statements of these students point to the recognition that it is necessary to teach writing at university; that this teaching should be specific; that one of the factors contributing to the process of appropriation of academic texts is the practice of writing them; and that the students can be a learning agent, by indicating to the teacher of RTP specific texts in their area.
\end{abstract}

Keywords: University; Academic Writing Teaching; Academic Genres

\footnotetext{
"Possui graduação em Letras pela Universidade Federal de Campina Grande, especialização em Tecnologias em Educação pela Pontifícia Universidade Católica do Rio de Janeiro, mestrado em Linguagem e Ensino pela UFCG e atualmente está cursando doutorado no Programa de Pós-Graduação em Educação na Universidade Federal de Minas Gerais. É professora da UFCG. Tem experiência na área de Linguística Aplicada ao ensino de Língua Portuguesa, desenvolvendo trabalhos principalmente sobre letramentos acadêmicos e escrita acadêmica. Seu endereço de email é professoraelizabethsilva@gmail.com

** Possui graduação em Letras pela Universidade Regional do Nordeste, mestrado em Letras pela Universidade Federal da Paraíba, doutorado e estágio pósdoutoral em Linguística pela Universidade Federal de Pernambuco. Professora do Programa de Pós-Graduação em Linguagem e Ensino da Universidade Federal de Campina Grande. Tem experiência na área de Linguística, com ênfase em Linguística Aplicada, atuando principalmente no ensino e na orientação de pesquisas sobre ensino de língua materna, formação de professor e análise de material didático. Seu endereço de email é freinaldo@uol.com.br
} 
142 Elizabeth Maria da Silva e Maria Augusta Gonçalves de Macedo Reinaldo, Escrita disciplinar:...

\section{Introdução}

No âmbito das discussões que vêm sendo realizadas, no Brasil, sobre a escrita acadêmica, este artigo focaliza o ensino dessa escrita na universidade. Ao cursarem as disciplinas constitutivas da grade curricular do curso de graduação ao qual estão vinculados, os estudantes, em maior ou menor proporção, são solicitados a produzir alguns (ou vários) textos acadêmicos - artigos científicos, ensaios, resenhas acadêmicas, projetos de pesquisa, entre outros. Como sabemos, esses textos são específicos, visto que são produzidos e circulam no contexto universitário; logo, aqueles que estão ingressando na academia tendem a desconhecê-los. No entanto, boa parte dos professores desconsidera essa não familiaridade dos alunos com a escrita acadêmica e a exige, partindo do pressuposto de que eles já a conhecem ou deveriam conhecê-la.

Para a pesquisadora Thereza Lillis (1999), que observou em uma universidade do Reino Unido como estudantes não tradicionais1 atribuem sentido à escrita do ensaio, existe uma prática institucional do mistério (institucional practice of mystery) que surge do conflito que se estabelece entre as expectativas dos professores e a dos alunos em relação ao que concebem como escrita acadêmica. A autora problematiza, assim, a ideia de que as convenções que orientam a escrita não são transparentes para aqueles que participam da comunidade acadêmica ou para aqueles que querem fazer parte dessa comunidade, ao mesmo tempo que defende a necessidade de um diálogo entre professores e alunos com vistas a melhor lidarem com esse "mistério" em torno da escrita.

Seguindo essa mesma perspectiva, o pesquisador Brian Street (2009), ao introduzir a ideia de letramentos acadêmicos (LEA; STREET, 1998) ${ }^{2}$ em um curso de verão sobre letramento, oferecido no Programa de PósGraduação em Educação, da Universidade da Pensilvânia, elaborou juntamente com os pós-graduandos uma lista flexível contendo dimensões presentes no processo de produção de texto que em geral não são explicitadas. Essas dimensões, denominadas por Street (op. cit.) de dimensões escondidas (hidden features), dizem respeito a enquadramento, contribuição, voz, ponto de vista, marcas linguísticas e estrutura. São aspectos da escrita recorrentemente esperados, nos textos acadêmicos, por professores, orientadores de trabalho de pesquisa, editores e pareceristas de revistas acadêmicas, mas que, na maioria das vezes, não são demonstrados por aqueles que escrevem, porque estes não os conhecem ou, em alguns casos, embora os conheçam, não sabem como materializá-los textualmente.

Esse cenário de "prática institucional do mistério" e "dimensões escondidas" da escrita acadêmica não está presente apenas nos contextos britânicos e americanos, respectivamente, mas também no brasileiro (MARINHO, 2010; FISCHER, 2011; PASQUOTTE-VIEIRA, 2014; CASTANHEIRA; STREET; CARVALHO, 2015). Entretanto, assim como Lillis (1999) e Street (2009), defendemos o ensino explícito da escrita acadêmica, pois as práticas de escrita vivenciadas na educação básica, embora extremamente necessárias e produtivas, não são suficientes para atender às demandas das práticas exigidas na educação superior, dado que a escrita não é um conjunto de habilidades linguísticas que, uma vez aprendidas, podem ser transferidas para quaisquer situações. Pelo contrário, a escrita é muito mais que habilidades, é também, e sobretudo, uma prática social (BAZERMAN, 2005) que varia de acordo com as áreas e disciplinas em que é requerida, assim como entre os diferentes contextos institucionais. Assim sendo, a escrita não deve ser ensinada a todos os estudantes de forma genérica, desconsiderando os contextos específicos de formação em que se encontram, mas com base nas suas necessidades disciplinares.

Nessa perspectiva, entendemos com Bazerman; Prior (2007 [2005]) que, quando o professor se empenha em conhecer a cultura disciplinar dos diferentes cursos nos quais atua, ${ }^{3}$ ele tem maior probabilidade de contribuir com a aprendizagem da leitura e da escrita daquele campo disciplinar. Dito de outra forma, quando esse professor busca analisar com os alunos de que maneira os textos e as práticas textuais refletem e criam certas relações sociais, ele está procedendo a um exame cuidadoso dos detalhes da linguagem e seus modos básicos de representação, produção, recepção e distribuição naquele campo.

Dessa forma, o professor deve despertar nos estu- 
dantes a consciência dos gêneros (DEVITT, 2009) específicos da comunidade disciplinar na qual aspiram inserir-se. Essa consciência, porém, não é alcançada com a compreensão apenas das convenções dos gêneros, mas também da funcionalidade dessas convenções como respostas a situações retóricas, a exemplo de orientações relativas ao uso de fontes de referência do conhecimento científico produzido na comunidade acadêmica. É com base nessas premissas que organizamos as aulas que ministramos para graduandos matriculados em diferentes cursos de graduação oferecidos em uma universidade pública do interior paraibano. Entretanto, não basta defender essa linha teórico-metodológica de ensino de escrita acadêmica, nem apenas aplicá-la, mas é preciso também avaliá-la. Para essa avaliação, a percepção do público-alvo para o qual o ensino está voltado é essencial, haja vista que o feedback dele poderá aprimorar e/ou redirecionar as ações desenvolvidas na disciplina e em disciplinas de natureza semelhante.

Assim sendo, pretendemos, no presente artigo, (1) descrever uma proposta de ensino da escrita para cursos de graduação orientada pelos princípios teórico-metodológicos que norteiam a abordagem de Escrita nas Disciplinas e (2) identificar e analisar as percepções de graduandos sobre a implementação desse tipo de metodologia de ensino da escrita. Para tanto, este texto está organizado em três seções: na primeira, apresentamos contribuições teóricas advindas da linha de estudos denominada escrita através do currículo e suas abordagens no âmbito dos contextos disciplinares; na segunda, apresentamos uma proposta de ensino da escrita para cursos de graduação orientada pelos princípios teórico-metodológicos que norteiam a abordagem da Escrita nas Disciplinas; na terceira e última, apresentamos evidências das percepções de graduandos sobre a implementação desse tipo de metodologia de ensino da escrita.

\section{Escrita através do currículo e suas abordagens}

O interesse pelo estudo da escrita em contextos disciplinares remonta à década de 1970, com a discussão acerca da necessidade de pesquisas sobre escrita não literária. Nos Estados Unidos, o movimento pedagógico Writing Across the Curriculum (WAC) se destacou por essa preocupação. Conhecido como um movimento de reforma do ensino superior, o WAC teve como objetivo inserir componentes curriculares de escrita nos semestres iniciais dos cursos de graduação, em resposta ao influxo para o ensino superior por meio de políticas abertas de admissão de grupos anteriormente excluídos. A primeira iniciativa foi a oferta de programas de escrita nas disciplinas para graduandos das engenharias e sua área de atuação, tendo em vista atender às queixas dos empregadores desses profissionais às universidades (BAZERMAN; RUSSELL, 2004; BAZERMAN et. al., 2005).

A literatura tem descrito duas abordagens da escrita através do currículo as quais, embora enfatizem ações distintas, podem ser desenvolvidas de forma associada. A primeira, denominada escrita para aprender (Writing to Learn - WTL), baseia-se na tese de que a compreensão do estudante pode melhorar por meio do processo da escrita: "Como posso saber o que eu penso até que eu veja o que eu digo?" (FOSTER apud BAZERMAN, 2005, p.57). Nesse sentido, a escrita funciona como uma ferramenta de auxílio na formação e na descoberta do conhecimento. McLeo; Margo (2000 [1992]), retomando o conceito de escrita expressiva do movimento britânico (cf. BRITTON, 1979, por exemplo) como ferramenta de aprendizagem focada no aprendiz, a associam ao conceito de escrita para aprender. Isso significa que os professores das mais variadas disciplinas podem usar a escrita como ferramenta de ensino-aprendizagem do conteúdo, associada à reflexão, resultando o pressuposto de que escrevemos para aprender e aprendemos com o que escrevemos. Inspirada no construtivismo vygotskyano, essa abordagem defende que ao escrever ensaios, diários, artigos, o estudante planeja e reflete sobre suas ideias, tornando-se construtor do seu conhecimento, por meio do planejamento, elaboração, revisão e edição de seu texto; por conseguinte, agente de sua aprendizagem.

Já a segunda abordagem, escrita nas disciplinas (Writing in Discipline - WID), é referida por McLeod; Margo (2000 [1992]) como a escrita transacional da linha de reflexão britânica, que parte, geralmente, do professor para os alunos. Nela a comunidade discursi- 
va disciplinar é decisiva, razão porque enfatiza a compreensão de como a escrita ocorre nas diferentes áreas do conhecimento, bem como a oferta de instruções de como as disciplinas devem ser estudadas. Nesse sentido, essa abordagem requer um olhar etnográfico, entendido como um olhar culturalmente sensível na busca de compreender significados da linguagem social e localmente situada (LUCENA, 2015). No caso específico de uma metodologia para identificação e análise de gêneros escritos nas diversas culturas disciplinares, o olhar etnográfico remete ao levantamento de produção, distribuição e uso de textos, tendo em vista a compreensão explícita do que os participantes denominam em uma determinada área disciplinar, visualizando as práticas nela implícitas (BAZERMAN, (2005[2004]). São recomendados os seguintes instrumentos e procedimentos: a) coleta dos textos usados, com anotações das ocasiões de uso, dos propósitos e do modo como as pessoas produzem, trabalham e interpretam esses textos; b) entrevista com participantes no processo de uso de textos, visando esclarecer significados, intenções, percepções e atividades desses participantes.

Nessa perspectiva, cabe ao professor de língua materna conhecer melhor as práticas de escrita que estejam de acordo com a necessidade dos estudantes. Uma consequência relevante desse modo integrado de pensar a escrita através do currículo é deixar de pensar no ensino de linguagem como atribuição exclusiva do professor de língua materna.

Em razão dos apoios administrativos e institucionais, no contexto americano, registrou-se seu crescimento e ampliação para os níveis de ensino fundamental e médio. São consideradas relevantes contribuições de autores, como Thaiss; Suhor (apud BAZERMAN et al., 2005), com a tese de que o aluno aprende mais ao refletir sobre o conhecimento, por meio da escrita; Elaine Maimon (apud BARWASHI; REIFF, 2010], com a observação sobre o potencial heurístico das configurações que formam nossa definição superficial de gênero: "Através de um estudo de gênero em todas as disciplinas de artes e ciências, podemos aprender mais a respeito das variedades de pensamento na academia e no mundo mais amplo da atividade profissional e pública" (p.247).
Podemos depreender que a abordagem escrita nas disciplinas (WID) é mais complexa que a abordagem escrita para aprender (WTL), pois requer, além do procedimento etnográfico representado pelo conhecimento das práticas de escrita desenvolvidas nas comunidades disciplinares alvo, o trabalho interdisciplinar, destacando as diferenças dos gêneros em diferentes situações acadêmicas e contextos sociais (BAZERMAN, 2009). Na subseção a seguir, são apresentados, de forma breve, alguns fundamentos teóricos.

\subsection{A escrita disciplinar e seu ensino}

A abordagem da escrita nas disciplinas configurou-se com o objetivo de dar maior atenção à relação entre escrita e leitura em contextos disciplinares específicos, considerando as possibilidades e os modos como essa relação pode ser adaptada à prática de ensino no âmbito acadêmico.

Originalmente, fundamentada na teoria cognitiva para explicar os processos de escrita (HAYS; FLOWER, 1980), a partir de meados da década de 1980, essa abordagem recebeu influência dos estudos linguísticos e etnográficos (BAZERMAN, 1988), segundo os quais a escrita se baseia em gêneros, devendo por isso ser entendida como uma forma de ação social com várias finalidades: persuadir autores diferentes a aderirem a um ponto de vista, correlacionar pontos de vista de autores diversos e externar seus próprios pensamentos como um modo de reflexão pessoal (BAZERMAN, 1995; BERKENKOTTER; HUCKIN, 1995).

Um conceito relevante nessa abordagem é o de cultura disciplinar. Becher (1981), estudando a cultura na educação superior, defende que as disciplinas são também fenômenos culturais: elas tomam forma ( $\mathrm{em}$ bodied) em grupos de pessoas que pensam de forma semelhante, com seus códigos de conduta, de valores e tarefas intelectuais distintas. Interpretando a estrutura e a natureza do conhecimento dentro de cada disciplina como dimensões centrais de diferenciação, Becher (1984) identificou quatro culturas disciplinares gerais, variando entre a cultura pura forte (hard pure culture) das ciências, a cultura pura leve (soft-pure culture) das humanidades e ciências sociais, a cultura aplicada dura 
(hard-applied culture) da engenharia e tecnologia e a cultura aplicada leve (soft-applied culture) das ciências sociais, como a educação e serviço social.

Hyland (2004[2000], p.8 a 11) usa a expressão cultura disciplinar como forma de ampliar/esclarecer o conceito de comunidade discursiva, usado por vários estudiosos da escrita acadêmica, como Swales (1990; [1992]2009). Para Hyland, as disciplinas podem ser vistas como sistemas, em que as crenças e as práticas interagem com normas, nomenclaturas, campos de conhecimento, conjunto de convenções, objetos e metodologias de pesquisa. Esses sistemas representam culturas disciplinares, manifestadas pelos respectivos discursos disciplinares e diferenciadas quanto ao conhecimento, aos objetivos, aos comportamentos sociais e às relações de poder (p.11). Dentro de cada cultura disciplinar os indivíduos adquirem competências discursivas especializadas que lhes permitem participar como membros do grupo.

Os gêneros, por sua vez, também sensíveis às variações disciplinares, constituem espaços de construção da cultura disciplinar. Considerando que os gêneros se materializam nas práticas textuais daqueles que os produzem, distribuem e consomem, e que os textos que os materializam são escritos para serem compreendidos dentro de determinados contextos culturais, a análise de gêneros chave pode prover insights sobre o que está implícito nas culturas acadêmicas e suas rotinas de operações retóricas, revelando percepções de valores e crenças do grupo. (p.12). Como têm mostrado os estudos sociorretóricos de gêneros, os campos disciplinares influenciam na distribuição das informações nos textos, indicando que cada comunidade acadêmica estabelece convenções, nomenclaturas e metodologias particulares para a composição dos textos que materializam os gêneros nela produzidos (cf. no contexto brasileiro o pioneiro estudo de MOTTA-ROTH, 1995).

Por ensino da escrita disciplinar, entendemos o ensino cujo objetivo é conduzir os graduandos a ler e a escrever em várias disciplinas, explorando as questões subjacentes às semelhanças e às diferenças, em termos de construção do conhecimento científico nas diversas áreas (BAZERMAN; PRIOR, 1995). Ainda de acordo com esses autores, os métodos de coleta de da- dos e os formatos para defender as especificidades do conhecimento disciplinar variam através do tempo, de disciplina para disciplina e mesmo dentro das disciplinas. Observando essa variação, Bazerman; Prior (2007[2005], p.178) consideram importante a mudança da noção de disciplina, baseada em comunidades de discurso como espaços sociais e/ou cognitivos unificados, para a noção de

\begin{abstract}
disciplinaridade (ênfase dos autores) como a constituição mediada e contínua de um tipo de rede social. A disciplinaridade invoca a integração do histórico e do situado, a produção tanto de conhecimento como do social, a prática dos experientes e dos novatos, a representação social da unidade e da hibridez dialógica da atividade concreta.
\end{abstract}

Assim, para testar, fundamentar e defender asserções em um campo específico, devem ser usados os tipos de dados ou evidências aceitos naquele campo, coletados e apresentados nos modos nele reconhecidos, num determinado espaço sócio-histórico.

Salientamos, nesse trabalho de construção do conhecimento científico, a participação dos aprendizes de pesquisador, o que justifica a preocupação com uma metodologia de ensino da escrita que contemple essa prática social. Nessa perspectiva, uma vez identificados o campo disciplinar do público-alvo do ensino e os tipos de questão pertinentes como objetos de estudo, delimita-se um conjunto de atividades didáticas que contemplem a leitura e a escrita de materiais de referência, em função dos métodos e formatos considerados apropriados à área do conhecimento em questão. A tese defendida por esses autores é de que vendo como ideias são desenvolvidas, testadas e apresentadas no campo específico de sua formação, o graduando pode compreender melhor o significado do que é lido e escrito no contexto da disciplina. Logo, perceberá que a escrita do conhecimento é um processo dinâmico preenchido com escolhas não só individuais, mas também socioculturais.

Esse quadro teórico-metodológico proposto para o ensino da escrita pode ser associado à prática da interdisciplinaridade como deslocamento de contexto, como 
propõe Noberto Etges (2011, p.84), ao tratar da construção do conhecimento científico:

um ato de deslocamento, um ato de transposição de um contexto para outro, numa palavra, um ato interdisciplinar. Neste sentido, $a$ interdisciplinaridade (ênfase do autor) é, em primeiro lugar, uma ação de transposição do saber posto na exterioridade para as estruturas internas do indivíduo, construindo o conhecimento.

Nessa perspectiva, Etges propõe duas estratégias de deslocamento baseadas no construtivismo. A primeira, denominada "estratégia do estranhamento interdisciplinar", consiste no estranhamento do cientista ao levar seu conhecimento para outros contextos, tendo para isso que adaptar/traduzir sua linguagem para se fazer entender. A segunda, a estratégia "da explicação ou esclarecimento pelo método do outro", com base no entendimento de que uma ciência pode se tornar objeto de outra. Nesse sentido, a interdisciplinaridade contribui para a construção da ciência: ao conhecer outros métodos, o cientista pode optar pela forma mais adequada de conduzir seus estudos. Isso significa que nenhuma ciência possui a verdade absoluta.

A nosso ver, cabe ao professor de Língua Portuguesa (na prática de leitura e escrita) o deslocamento em busca da interface com os profissionais das áreas específicas, com o objetivo de conhecer os usos e os significados das práticas textuais da área de formação com que está trabalhando.

Esse diálogo interdisciplinar fornece subsídios para seleção de conteúdos - gêneros de texto, considerados em seus componentes funcional e linguístico-textual, e temáticas relacionadas com os interesses do alunado alvo -, e para alternativas metodológicas que priorizem atividades com vistas à integração dos alunos na cultura disciplinar do seu curso, a partir do reconhecimento dos gêneros que nela são produzidos.

Na seção a seguir, descrevemos uma proposta de ensino da escrita para cursos de graduação, elaborada com base nessas premissas da abordagem de ensino de escrita nas disciplinas e implementada nas aulas que ministramos para estudantes matriculados em diferen- tes cursos oferecidos em uma universidade pública do interior da Paraíba.

\section{A escrita envolvendo fontes como primeiro passo para inserção de graduandos na comuni- dade disciplinar}

Considerando o interesse especializado da educação superior, entendemos com Bazerman (1995) que a escrita nessa esfera depende, cada vez mais, de que o escritor seja informado pelo conhecimento do seu campo de especialização. A expectativa da comunidade acadêmica (os professores e os alunos (pares)) é de que as declarações e os julgamentos do escritor em formação se baseiem no seu crescente corpo de conhecimento, no material lido, aprendido, avaliado e construído por ele.

Orientado por essa visão, o autor propõe um conjunto de práticas de escrita relacionadas com a leitura de fontes de referência da área de conhecimento/formação acadêmica. Tais práticas apresentam uma escala de complexidade, em termos de habilidades a serem dominadas, que podem ser agrupadas em atividades de reconhecimento (as anotações e diários de leitura, parafrasagem, sumarização de ideias centrais do autor, reconhecimento das vozes nos textos), atividades de análise/ ensaios (de objetivos e técnicas de um autor, comparação e síntese de fontes) e, por último, atividades de criação do conhecimento (leitura e escrita de artigos de pesquisa nas diversas áreas do conhecimento).

Alinhando-nos a essa proposta, temos procurado cumprir os dois primeiros níveis da escala de complexidade das atividades aplicadas no âmbito do componente curricular Leitura e Produção de Textos, com 60 horas-aula, oferecido aos graduandos do primeiro período dos diversos cursos de uma universidade pública do interior paraibano. Para isso, antes do início do período letivo, estabelecemos contatos com professores da formação profissional do Curso a que estão vinculados os alunos matriculados na referida disciplina. Com esse deslocamento, pretendemos conhecer as necessidades do alunado-alvo, quanto a gêneros e temáticas pertinentes como objetos de estudo nos períodos subsequentes, e planejar ações de modo a despertar seu interesse e motivação por esse componente curricular, 
envolvendo-se na busca das fontes de conhecimento da sua área de formação.

Uma vez estabelecida essa interação com os professores do Curso em questão, organizamos a disciplina LPT em três unidades orientadas por diferentes objetivos e atividades propostas, conforme apresentamos no quadro resumitivo a seguir e detalhamos a posteriori:

Quadro 1 - resumo do planejamento da disciplina LPT

\begin{tabular}{|c|c|c|}
\hline Unidades da disciplina & Objetivos das unidades & Atividades propostas nas unidades \\
\hline $\begin{array}{l}\text { Primeira: leitura e produção do } \\
\text { resumo acadêmico }\end{array}$ & $\begin{array}{l}\text { Promover a familiarização do } \\
\text { alunado-alvo com as instâncias de } \\
\text { comunicação científica e as respec- } \\
\text { tivas normas para publicação na } \\
\text { área de formação em foco. }\end{array}$ & $\begin{array}{l}\text { (1) reconhecimento das unidades infor- } \\
\text { macionais presentes na textualização de } \\
\text { resumos acadêmicos que antecedem os } \\
\text { trabalhos completos publicados em anais } \\
\text { de eventos de iniciação científica; } \\
\text { (2) exercício da textualização escrita } \\
\text { do gênero, condensando e preservando } \\
\text { as unidades informacionais do resumo } \\
\text { original, em função das exigências da } \\
\text { situação de comunicação acadêmica } \\
\text { simulada; } \\
\text { (3) reflexão sobre os requisitos textuais e } \\
\text { linguísticos para o desempenho adequa- } \\
\text { do da tarefa de condensar resumos; } \\
\text { (4) e (5) escrita do gênero resumo } \\
\text { acadêmico. }\end{array}$ \\
\hline $\begin{array}{l}\text { Segunda: análise de exemplares de } \\
\text { artigo de revisão de literatura }\end{array}$ & $\begin{array}{l}\text { Preparar os alunos para a prática } \\
\text { de escrever sobre o que se apreende } \\
\text { da leitura de fontes do conhecimen- } \\
\text { to especializado. }\end{array}$ & $\begin{array}{l}\text { (6) observação das funções do gênero } \\
\text { artigo; } \\
\text { (6a) reconhecimento de como se dá a } \\
\text { gestão das vozes no texto; } \\
\text { (6b) identificação do posicionamento do } \\
\text { autor do texto. }\end{array}$ \\
\hline $\begin{array}{l}\text { Terceira: planejamento, produção } \\
\text { e apresentação de um artigo de } \\
\text { revisão de literatura }\end{array}$ & $\begin{array}{l}\text { Mediar o processo de planejamento, } \\
\text { produção e apresentação oral de um } \\
\text { artigo de revisão de literatura. }\end{array}$ & $\begin{array}{l}\text { Atividades de textualização do gênero } \\
\text { artigo de revisão de literatura: escrita/re- } \\
\text { visão/reescrita das seções constitutivas; } \\
\text { Defesa oral do artigo. }\end{array}$ \\
\hline
\end{tabular}

Fonte: as autoras 
Conforme sinalizamos no quadro 1, a primeira unidade da disciplina LPT destina-se à leitura e à escrita do resumo acadêmico, com foco na relação entre o uso das regras de sumarização (MACHADO et al., 2004; LEITE, 2009) e a situação comunicativa acadêmica determinante da configuração textual desse gênero (MOTTA ROTH; HENDGES, 2010). O conjunto de atividades elencadas a seguir tem em vista a familiarização do alunado-alvo com as instâncias de comunicação científica e as respectivas normas para publicação na área de formação em foco:

(1) Leia, com atenção, os resumos acadêmicos extraídos dos Anais do X CIC - Congresso de Iniciação Científica (PIBIC/CNPq/UFCG 2012/2013), para resolver as tarefas a seguir:

a) Com base nas informações sobre a organização textual do resumo acadêmico/abstract (LEITE, 2009; MOTTA ROTH; HENDGES, 2010; SILVA, 2012), identifique as partes da pesquisa contempladas na organização desses resumos.

b) Aponte os marcadores linguísticos dessas partes.

(2) O resumo expandido (900 palavras), abaixo transcrito, foi publicado nos Anais da $66^{a}$ Reunião da SBPC (Sociedade Brasileira para o Progresso da Ciência - 2014).

Com a finalidade de divulgar sua pesquisa em outro evento, os autores deverão se inscrever mediante o envio de um resumo condensado (aproximadamente 300 palavras) a ser publicado no Caderno de Programação.

Proceda à condensação desse resumo, observando as estratégias de sumarização (LEITE, 2009). Na nova edição, o resumo deverá preservar as unidades informacionais do resumo original, sinalizadas por marcadores linguísticos.

(3) Analise o grau de adequação dos resumos condensados a seguir, considerando os seguintes aspectos:

a) organização textual (presença das partes constitutivas do resumo acadêmico fonte-contextualização, objetivo(s), referencial teórico e/ ou metodológico, resultados, conclusão) e configuração paragráfica;

b) regras de sumarização utilizadas e fidelidade ao conteúdo do resumo fonte (LEITE, 2009); c) norma linguística padrão (articulação entre as frases (coesão), uso dos tempos verbais, concordância e regência verbal e nominal, sinais de pontuação, ortografia, acentuação gráfica).

Reescreva os resumos, aponte soluções para os problemas encontrados.

(4) Faça o resumo acadêmico que deve anteceder o artigo de Lucila Ishitani em anexo. Neste resumo, devem constar o objetivo, breve alusão ao trabalho desenvolvido e aos resultados obtidos. (entre 7 e 10 linhas)

(5) Cite três palavras-chave que poderiam figurar no artigo.

A atividade (1) enfoca o reconhecimento das unidades informacionais presentes na textualização de resumos acadêmicos que antecedem os trabalhos completos publicados em anais de eventos de iniciação científica. A atividade (2), partindo do conhecimento adquirido pelo aluno na atividade (1), leva ao exercício da textualização escrita do gênero, condensando e preservando as unidades informacionais do resumo original, em função das exigências da situação de comunicação acadêmica simulada. A atividade (3) proporciona a reflexão sobre os requisitos textuais e linguísticos para o desempenho adequado da tarefa de condensar resumos. E as atividades (4) e (5), considerando os conhecimentos adquiridos nas atividades anteriores, propõem a escrita do gênero resumo acadêmico.

A segunda unidade destina-se à busca de conceitos, temas-problema, na sua maior parte, sugeridos pelos professores do curso de origem, e definidos com base em fontes de referências (impressas e digitais). Trata-se da preparação para a prática de escrever sobre o que se apreende da leitura de fontes do conhecimento especializado. Simultaneamente, são desenvolvidos dois tipos de ações de ensino-aprendizagem:

a. análise de exemplares de artigo de revisão de literatura $^{4}$ (também referido em algumas áreas como revisão teórica ou revisão sistemática). A sequência de atividades aplicadas nessa etapa busca chamar atenção para as funções desse gênero, como dar crédito à criação intelectual de outro(as) autores(as); qualificar o autor como membro de deter- 
minada cultura disciplinar ao familiarizar-se com a produção de conhecimento prévia na área; emprestar uma voz de autoridade e posicionamento intelectual ao texto (MOTTA-ROTH; HENDGES, 2010, p.90). São também enfatizadas as suas formas de textualização em atividades como a prescrita em (6).

(6) Com base na leitura e discussão do capítulo "Artigo acadêmico: revisão de literatura" (MOTTA-ROTH; HENDGES, 2010, p. 89110), observe o artigo "Aprendizagem colaborativa no ensino presencial: TICs ajudam ou atrapalham?", de Lucila Ishitani, e resolva as questões a seguir:

a) Verifique, na seção 2 (2.1 e 2.2), como é feita a revisão da literatura, em termos de citação em bloco, direta ou indireta. Ilustre sua resposta com passagem da seção.

b) Resuma, com suas palavras, as críticas feitas, nesta seção, ao modelo tradicional de ensino e às ideias centrais do modelo de aprendizagem colaborativa. (máximo de 5 linhas)

Essa atividade contempla, de um lado, o reconhecimento de como se dá a gestão das vozes no texto (6a); de outro, a identificação, através da estratégia da construção, do posicionamento do autor do texto (6b).

b. planejamento e escrita de um artigo de revisão. Partimos da informação de que esse gênero não trata de um conhecimento novo, mas apenas supre as lacunas de conhecimento que o pesquisador tem em determinada área, constituindo-se o primeiro passo para a formulação de um problema de pesquisa (WAZLAWICK, 2009). Suas principais funções são, entre outras, dar crédito à criação intelectual de outros autores, e indicar que nos qualificamos como participantes de determinada cultura disciplinar (MOTTA-ROTH; HENDGES, 2010). Para construir-se como um gênero que atenda ao rigor científico, deve ser bem planejado e conduzido, observando os requisitos em termos de informações presentes em cada uma das seções que o constituem.
Com o objetivo de conduzir os alunos à prática da escrita desse gênero que se constrói sobre a leitura das fontes de referência especializadas de cada área do conhecimento, temos adotado, a partir das contribuições de Motta-Roth; Hendges (2010), um modelo simplificado de descrição sociorretórica, tendo em vista atender à prática da iniciação científica. O modelo de referência adotado constitui-se das seguintes seções e respectivas unidades informacionais:

1) Introdução, com textualização marcada pelas seguintes unidades informacionais: declarar a importância do tema, fazer generalização sobre itens de pesquisa prévia, identificar lacunas no conhecimento, esboçar o(s )objetivo(s) e anunciar a estrutura do artigo.

2) Metodologia ou procedimentos metodológicos, textualizada com informações sobre como, onde e com que a pesquisa foi feita, o que implica descrição detalhada indicando a fonte dos dados, o tamanho/dimensão da amostra, os critérios para a coleta dos dados.

3) Revisão de literatura: dois movimentos textualizam esta seção: a) estabelecer interesse profissional no tópico com generalizações sobre ele; b) detalhar a revisão citando, contra-argumentando e indicando lacunas em pesquisas prévias. Procura-se mostrar os pontos de vista convergentes e divergentes dos autores; explicitando os enfoques recebidos pelo tema na literatura publicada.

4) Análise e discussão dos resultados, seção em que se comentam, comparam ou contrastam a(s) questão (ões) teórica(s) de determinada área de conhecimento selecionada(s) como objeto de estudo.

A terceira e última unidade tem sido destinada às atividades de textualização desse gênero: escrita/ revisão/reescrita (individual ou em grupos de dois alunos) das quatro seções constitutivas. Nessa etapa, são monitorados, em sessões agendadas, aspectos referentes ao foco dado à organização retórica e à caracterização linguística de cada seção. Encerra-se o curso com a defesa oral do artigo, evento para o qual os alunos são sensibilizados, em função da caracterização e uso da oralidade formal acadêmica (AQUINO, 2007; XAVIER, 2010). 
O percurso estabelecido para a textualização do artigo pode ser discutido, desenvolvido, melhorado, reformulado, por meio do recursivo processo de avaliação docente e discente. Nesse sentido, temos verificado a necessidade de proceder a frequentes ajustes para, no espaço de um semestre letivo, vencer desafios em duas direções: de um lado, ampliar a rede de contatos com os membros da comunidade disciplinar do público-alvo, instigando os alunos a se aproximarem de professores e de colegas de períodos subsequentes, estimulando o interesse em se apropriar de conhecimentos relacionados à sua área de formação; de outro, acentuar cada vez mais o processo de escrita acadêmica, com a intensificação de tarefas que contemplem habilidades exigidas para a escrita envolvendo fontes de referência e as dimensões contextuais, textuais e linguísticas dos gêneros acadêmicos enfocados.

No plano discente, a fim de aprimorarmos esse percurso, solicitamos o feedback dos alunos do curso de Ciência da Computação que cursaram a disciplina LPT. Para isso, elaboramos um questionário organizado em três partes (ver Anexo 1): (1) Avalie a atuação docente; (2) Avalie sua atuação como aluno; (3) Opiniões, comentários, sugestões, reclamações. Essa terceira parte, que focalizamos na próxima seção, é constituída de três perguntas discursivas: (1) Você considera importante o ensino da escrita de textos específicos de sua área na disciplina LPT? Por quê? (2) As atividades desenvolvidas ao longo da disciplina LPT têm colaborado com outras disciplinas e/ou atividades acadêmicas? De que forma? (3) Que sugestões você pode apresentar visando a uma contribuição mais efetiva da disciplina para a formação profissional do graduando? Esse questionário foi aplicado, via eletrônica, acompanhado de um termo de consentimento livre e esclarecido, com estudantes que cursaram LPT em três períodos letivos (2010.2, 2012.2 e 2013.1). Enviamos o questionário para vinte alunos, selecionados aleatoriamente, mas apenas dez deles responderam. A seguir, analisamos o que disseram esses participantes sobre o ensino de escrita acadêmica que tiveram na disciplina LPT.

\section{Percepções de graduandos quanto à metodo- logia de ensino de escrita acadêmica}

As respostas dadas pelos graduandos ao questionário aplicado evidenciam o reconhecimento de que o deslocamento de contexto (ETGES, 2011) construído a partir do estabelecimento de uma relação interdisciplinar - Língua Portuguesa e Ciência da Computação - favoreceu o desenvolvimento de um trabalho centrado nas especificidades disciplinares do público-alvo da disciplina LPT, embora alguns ajustes devam ser feitos.

Vejamos o que afirmam alguns dos estudantes, quando indagados sobre o ensino de escrita de textos específicos da área da qual fazem parte:

É essencial o ensino da escrita em qualquer curso universitário, em todos há o uso da mesma. Em Computação, há a necessidade de produção de artigos científicos, relatórios, conversações, entre diversas outras situações em que o uso da escrita acadêmica será exigida. $(\mathrm{S} 4)^{5}$

O aluno entra na universidade acostumado ao ritmo do ensino médio, acostumado a ter aulas sobre os mais diversos assuntos. Eu, pessoalmente, me habituei a sempre ter aulas de Gramática, eu valorizava e gostava muito disso. LPT introduz, apresenta e ensina ao aluno como produzir textos acadêmicos, essenciais para o decorrer da sua graduação. (S6)

Saber como escrever textos específicos na área da computação é muito importante, principalmente quando tratamos de Ciência da Computação. Um profissional de Ciência da Computação deve estar preparado para além de resolver problemas utilizando técnicas computacionais também poder documentar e divulgar o seu trabalho. Um bom cientista deve ser um bom escritor. (S1)

Além de tornar a disciplina mais interessante já que vemos textos específicos da área, é importante conhecer características dos textos técnicos e comparar com textos de outras áreas e outros formatos. (S5)

Nesses depoimentos, os sujeitos reconhecem a importância de ensinar e aprender a escrever textos espe- 
cíficos da cultura disciplinar da qual estão fazendo parte, no caso, o curso de Ciência da Computação. Para S4, por exemplo, "é essencial o ensino da escrita em qualquer curso universitário. Em Computação, há a necessidade de produção de artigos científicos, relatórios (...)". Subjacente a essa afirmação de S4 está o reconhecimento de que, embora os graduandos tenham passado por um processo de escolarização, em que devem ter tido experiências com a escrita escolar, essa aprendizagem não é suficiente para atender às exigências da escrita disciplinar, por isso destaca a necessidade de ensiná-la. Subjaz, também, a essa assertiva de $\mathrm{S} 4$ o entendimento de que, dentro da própria universidade, há especificidades, razão pela qual cita alguns gêneros exigidos no Curso de Computação que poderiam ser ensinados. O graduando percebe, assim, que a escrita não é algo homogêneo nem uniforme que, quando aprendido, pode ser aplicado em qualquer situação, conforme crença criticada por Carroll (2002), mas concebe-a como uma prática social (BAZERMAN, 2005); logo, situada e perpassada pelos discursos disciplinares que a constituem como tal.

S6 também compartilha dessa visão de S4 de que cada cultura disciplinar (HYLAND, 2004 [2000]) tem as suas especificidades e, assim, no processo de transição de uma cultura para outra, o ensino da escrita disciplinar (BAZERMAN; PRIOR, 2007 [2005]) se faz relevante na medida em que se configura como um espaço de construção da cultura da qual os estudantes estão começando a participar. S6 destaca o ensino dessa escrita, pois é ciente de que, diferentemente do ensino médio em que são recorrentes as aulas de gramática - "Eu, pessoalmente, me habituei a sempre ter aulas de Gramática" -, na universidade, deveria escrever textos acadêmicos - "LPT [uma disciplina ofertada no seu curso] introduz, apresenta e ensina ao aluno como produzir textos acadêmicos, essenciais para o decorrer da sua graduação". Ao citar a disciplina LPT como um espaço de ensino da produção de textos acadêmicos com os quais ele ainda não tinha familiaridade, $\mathrm{S} 6$ evidencia tal disciplina como uma possibilidade para o processo de integração dos graduandos na cultura disciplinar na qual estão inseridos, porém não necessariamente integrados.

S1 e S5 ratificam, igualmente, a importância de aprender a escrever textos específicos - "saber como es- crever textos específicos na área de computação é muito importante" e "a disciplina [é] mais interessante já que vemos textos específicos da área", respectivamente. Essa preocupação em conhecer e saber como se escrevem os textos específicos da área sinaliza, mais uma vez, a compreensão da escrita enquanto uma prática heterogênea, mutável, que se constitui e é constituída na cultura disciplinar em que circula. S5 destaca, inclusive, a possibilidade de "conhecer as características dos textos técnicose comparar com textos de outras áreas e outros formatos". Subjacente a essa assertiva de S5, à semelhança do que observamos nas assertivas dos demais sujeitos (1, 4 e 6), está o entendimento de que as práticas de escrita são plurais e socialmente situadas nas culturas disciplinares em que se configuram.

Além dessas reflexões sobre a metodologia de ensino de escrita acadêmica adotada na disciplina LPT, os sujeitos apresentaram algumas sugestões para o aprimoramento de tal disciplina. Vejamos algumas delas:

Eu acho que no primeiro período do curso o aluno não tem maturidade suficiente para aproveitar por completo o que a disciplina pode oferecer. Embora o aluno aperfeiçoe sua habilidade de escrita a produção científica necessita de mais conhecimento e maturidade. (S2)

Sugiro mais atividades no campo da escrita, para que a prática facilite mais ainda o desenvolver de textos acadêmicos. (S3)

É importante a participação dos alunos indicando textos técnicos, documentações e manuais que são desenvolvidos em disciplinas específicas do curso (de Computação, no caso), pois muitos sentem dificuldade na elaboração de documentações de sistemas computacionais, por exemplo, justamente por não conhecer este tipo de texto. Acredito que o professor possa utilizar disto ao máximo para diminuir a distância que muitos alunos da área de exatas sentem da área de humanas e praticar a leitura e a escrita de textos de uma forma mais próxima da sua área de atuação. (S5)

As sugestões expostas acima apontam para aspectos que evidenciam a maturidade dos alunos no tocante ao planejamento da disciplina LPT. Para S2, essa disciplina não deveria ser ministrada no primeiro período 
do curso, porque "o aluno não tem maturidade suficiente para aproveitar por completo o que a disciplina pode oferecer". Talvez, a ausência de maturidade mencionada por S2 seja explicada pelo fato de que o objeto de estudo da disciplina LPT são textos acadêmicos, ou seja, textos específicos do contexto universitário, portanto, desconhecidos, em geral, daqueles que estão começando a ingressar na cultura disciplinar. Em virtude disso, LPT pode se configurar como complexa para o seu público -alvo, somando-se ao fato de que a "produção científica necessita de mais conhecimento e maturidade" (S2). Essa sugestão de S2 serve como um alerta para os professores que ministram LPT (ou disciplinas semelhantes), para que, de um lado, possam considerar que os graduandos não conhecem os textos acadêmicos e que, portanto, esses textos precisam ser ensinados; de outro, possam ampliar a indicação de fontes especializadas da cultura disciplinar alvo de modo que os discentes tenham a possibilidade de conhecer um pouco mais os discursos da sua cultura disciplinar e, assim, estarem, ainda que muito inicialmente, cientes de como se escrevem (e eles podem escrever) textos especializados de sua área.

Para S3, uma das formas de aprender os textos acadêmicos é praticá-los - "mais atividades no campo da escrita, para que a prática facilite mais ainda o desenvolver de textos acadêmicos". Ele reconhece que, para aprender a escrever textos acadêmicos, não basta apenas conhecer a teoria, saber como se escreve, mas é preciso sobretudo exercitar a escrita, praticá-la. Essa sugestão de S3 aponta, assim, para a premissa de que quanto mais escrevemos (e reescrevemos) os nossos textos, mais os aprimoramos e conseguimos desenvolvê-los de modo mais adequado ao público-alvo.

Por fim, para S5, não cabe apenas ao professor o papel de buscar os textos específicos da área e apresentá-los aos alunos, mas "é importante a participação dos alunos indicando textos técnicos, documentações e manuais que são desenvolvidos em disciplinas específicas do curso (de Computação, no caso), pois muitos sentem dificuldade na elaboração de documentações de sistemas computacionais, por exemplo, justamente por não conhecer este tipo de texto". S5 acredita que pode contribuir para o planejamento de LPT, pois, por estar cursando disciplinas específicas do seu curso de Ciência da
Computação, poderá indicar para o professor as fontes e os materiais que são adotadas pelos professores dessas disciplinas. Assim sendo, o professor de LPT poderá planejar a disciplina, considerando as necessidades do seu público-alvo elencadas por esse mesmo público, além do contato direto com profissionais da área, como fizemos. Essa sugestão de S5 sinaliza seu interesse em aprender a escrever os textos que são específicos da sua área, os quais inclusive estão sendo exigidos em disciplinas que está cursando. Essa possibilidade de que os alunos indiquem para o professor de LPT textos específicos é o primeiro passo para que eles assumam o papel de etnógrafos do seu curso, nos termos de Johns $(1997,2002)$.

\section{Considerações finais}

Com base nos pressupostos norteadores da abordagem escrita nas disciplinas, descrevemos uma proposta de ensino da escrita que implementamos em cursos de graduação, bem como exploramos as percepções de graduandos sobre essa metodologia de ensino de escrita.

Entendemos que o ensino de escrita deve ser realizado conforme as necessidades disciplinares dos graduandos de áreas diversas. Defendemos que cabe ao professor de Língua Portuguesa o deslocamento em busca da interface com os profissionais das áreas específicas, a fim de conhecer os usos e os significados das práticas textuais dessas áreas de formação e, assim, ter mais subsídio para ensinar a escrita nesse contexto. Defendemos também a necessidade de o professor de Língua Portuguesa manter no ensino da escrita o equilíbrio entre a consciência da funcionalidade do gênero e o domínio do componente linguístico-textual desse gênero, com atividades de leitura, escrita e reescrita.

Os depoimentos de graduandos com quem aplicamos essa metodologia de ensino da escrita acadêmica fortalecem a nossa argumentação, uma vez que apontam para o reconhecimento de que é necessário ensinar na universidade a escrita dos textos específicos da área, já que são diferentes dos textos aprendidos na educação básica; de que esse ensino deve ser específico, respeitando as particularidades das culturas disciplinares 
nas quais são produzidos; de que um dos fatores que contribuem para o processo de apropriação dos textos acadêmicos é a prática de escrevê-los; e de que o aluno pode ser um agente da aprendizagem, indicando para o professor de LPT textos recorrentes em sua área.

Em suma, esses depoimentos ratificam a produtividade do diálogo interdisciplinar, o qual fornece subsídios para a seleção de conteúdos (gêneros de texto e temáticas relacionadas com os interesses do alunado alvo) e para a adoção de alternativas metodológicas (reconhecimento dos gêneros produzidos na comunidade do curso do aluno; e para a manutenção no ensino da escrita do equilíbrio entre a consciência da funcionalidade do gênero e o domínio do componente linguístico-textual desse gênero, com atividades de leitura e escrita, bem como do exercício da reescrita orientada). Entretanto, reconhecemos que ainda precisamos lidar com alguns desafios, a exemplo de solicitar dos alunos mais produções textuais, como sugerido por S3. O desafio se instaura tendo em vista a realidade de muitas universidades públicas brasileiras, como a que realizamos a experiência ora relatada: nem sempre é possível praticar ainda mais a escrita, como gostaríamos, haja vista a quantidade de alunos (em média cinquenta e cinco a sessenta por turma) e a realização de outras atividades que são exigidas aos docentes, tais como publicação de artigos acadêmicos, orientações, participações em bancas, ministração de cursos de extensão, participação em atividades burocráticas, dentre outras. No entanto, apesar desse impasse, entendemos, e defendemos, que a solicitação da escrita e reescrita de textos acadêmicos, acompanhada de feedbacks dados pelos professores, é essencial à aprendizagem dos discentes, caso contrário, eles não teriam como evoluir no processo de integração na cultura disciplinar da qual fazem parte. Assim, cabe a nós, professores, imersos nesse contexto de muitas exigências, não nos esquecermos de que a formação dos discentes deve ser a nossa prioridade. Precisamos fazer os ajustes necessários à realidade de cada sala de aula $\mathrm{e}$ continuarmos acreditando que é possível, sim, contribuir com esse processo de integração dos graduandos à cultura disciplinar, ainda que ocorra paulatinamente e em pequena escala.

\section{Agradecimentos}

Agradecemos aos professores do curso de Ciência da Computação que nos ajudaram a conhecer um pouco mais as necessidades dos alunos desse curso quanto a gêneros e temáticas recorrentes nessa área. Agradecemos, igualmente, aos graduandos que deram um feedback sobre a metodologia de ensino de escrita acadêmica que adotamos na disciplina LPT por eles cursada. Com certeza, a contribuição desses docentes e discentes foi crucial para o aprimoramento das ações que desenvolveremos nessa disciplina destinada a cursos de natureza semelhante.

\section{Notas}

1. 'Não-tradicional' é o discurso institucional para se referir a indivíduos de grupos sociais anteriormente excluídos da educação superior na Grã-Bretanha.

2. Modelo de escrita em que esta é vista como uma prática ideológica, envolvida por relações de poder e perpassada por significados e práticas culturais específicos.

3. Estamos nos referindo à realidade presente em algumas universidades, em que o professor de Língua Portuguesa ministra, para alunos de diferentes cursos de graduação, uma disciplina cujo foco é o trabalho com a leitura e a escrita acadêmica.

4. Na escala de complexidade das habilidades de escrever sobre a leitura, proposta por Bazerman (1995), as atividades de desenvolvimento de respostas a leituras de fontes se configuram como ensaios, que envolvem passos como argumentação, comparação, síntese. $\mathrm{Na}$ visão do autor, trata-se dos requisitos iniciais para o uso mais disciplinado de evidências nas especialidades no âmbito dos contextos acadêmico e profissional.

5. A letra $S$, que significa Sujeito, diz respeito aos graduandos que responderam ao questionário.

\section{Referências}

AQUINO, I. de S. Como falar em encontros científicos: do seminário em sala de aula a congressos internacionais. $3^{\text {a }}$ ed. João Pessoa: Editora Universitária/UFPB, 2007.

BARWASHI, A. S.; HEIFF, M. J. Genre - An introduction to history, theory, research, and pedagogy. Fort Collins: The WAC Clearinghouse, 2010.

BAZERMAN, C. Genre and Cognitive Development: Beyond Writing to Learn. In: BAZERMAN, C.; 
BONINI, A.; FIGUEIREDO, D. (Eds.). Genre in a changing world. Fort Collins: The WAC Clearinghouse/West Lafayette: Parlor Press, 2009. 279294.

BAZERMAN, C. The informed writer: using sources in the disciplines. Boston, Toronto: Hought Mifflin Company, 1995. 379-389.

Shaping written knowledge: The genre and activity of the experimental article in science. Madison, WI: University of Wisconsin Press, 1998.

Gêneros Textuais, tipificação e interação. São Paulo: Cortez, 2005 [2004].

BAZERMAN, C.; PRIOR, P. A participação nos mundos socioletrados emergentes. In: HOFFNAGEL, J.C.; DIONÍSIO, A.P. (Orgs.). Escrita, gênero e interação social. São Paulo: Cortez, 2007 [2005]. 150-197.

BAZERMAN, C; RUSSELL, D. (Eds.). Writing selves/ writing society. Retrieved from Colorado State University, WAC Clearinghouse: http://wac.colostate. edu/books/selves_society/. 2004.

BAZERMAN, C.; LITTLE, J.; BETHEL, L.; CHAVKIN, T.; FOUQUETTE, D.; GARUFIS, J. Reference Guide to Writing Across the Curriculum. Parlor Press and The WAC Clearinghouse, 2005.

BECHER, T. (1981). Towards a Definition of Disciplinary. Cultures, Studies in Higher Education, VI, 109-122.

(1984). The Cultural View. In B. R. Clark (Ed.), Perspectives on Higher Education: Eight Disciplinary and Comparative Views (Berkeley, CA: University of California Press).

BERKENKOTTER, C; HUCKIN, T. Genre knowledge in disciplinary communication: Cognition/culture/ power. Hillsdale, NJ: Lawrence Erlbaum, 1995.

BRITTON, J. Language and learning. London: Penguin, 1979.

CARROLL, A. L. Rehearsing New Roles: how college student develop as writers. Illinois: Southern Illinois University Press, 2002.

CASTANHEIRA, M. L.; STREET, B.; CARVALHO, G. Navigation across academic contexts: Campo and Angolan students in a Brazilian university. In.: GREEN; J. L; BAKER, W. D. Pedagogies - an Internacional Journal. Routledge, vol. 10, no 1, January-March, 70$85,2015$.

DEVITT, A. J. Teaching Critical Genre Awareness. In: BAZERMAN, C.; BONINI, A.; FIGUEIREDO, D. (Orgs.). Genre in a Changing World. Fort Collins: The WAC Clearinghouse and Parlor Press, 2009. 342-355.

ETGES. N. J. Ciência, interdisciplinaridade e educação. In: JANTSCH, A.P; BIANCHETTI, L. (Orgs.).
Interdisciplinaridade para além da filosofia do sujeito, Petrópolis. Rio de Janeiro: Vozes, 2011. 60-94.

FIAD, R. S. A escrita na universidade. Revista da ABRALIN, v. Eletrônico, n. Especial, 357-369, 2011.

FISCHER, A. Sentidos situados em eventos de letramento na esfera acadêmica. Educação, Santa Maria, v. 35, n. 1, p. 215-228, maio/ago, 2010. Disponível em: http:// www.ufsm.br/revistaeducacao. Acesso em 28 de maio de 2014.

. Práticas de letramento acadêmico em um curso de Engenharia Têxtil: o caso dos relatórios e suas dimensões escondidas. Scripta, v. 16, 54-67, out., 2011.

HAYS, J. R.; FLOWER, L. S. Identifying the organization of writing processes. In: GREGG, L. W.; STEINBERG, E. R. (Ed.). Cognitive processes in writing. New Jersey: Lawrence Erlbaum Associates, 1980. 3-30.

HYLAND, K. Disciplinary discourse: social interactions in academic writing. London: Longman, 2004 [2000].

JOHNS, A. M. Text, Role and Context: Developing Academic Literacies. Cambridge: Cambridge University Press, 1997.

(Ed). Genre in the Classroom: Multiple Perspectives. Mahwah, NJ: Lawrence Erlbaum, 2002.

LEA, M. R; STREET, B. V. Student writing in higher education: an academic literacies approach. Studies in Higher Education, v. 23, issue 2, jun., 157, 1998.

LEITE, M. Q. Resumo. São Paulo: Editora Paulistana, 2009.

LILLIS, T. Whose 'Common Sense'? Essayist literacy and the institutional practice of mystery. In: JONES, C.; TURNER, J.; STREET, B. (orgs.). Students writing in the university: cultural and epistemological issues. Amsterdam: John Benjamins, 127-140, 1999.

LILLIS, T.; SCOTT, M. Defining academic literacies research: issues of epistemology, ideology and strategy. Journal of Applied Linguistics, 4, 5-32, 2007.

LUCENA, Maria Inêz Probst. Práticas de linguagem na realidade da sala de aula: contribuições da pesquisa de cunho etnográfico em Linguística Aplicada. D.E.L.T.A., 31-especial, 2015, (67-95).

MACHADO, R; LOUSADA, E.; ABREU-TARDELLI. Resumo. São Paulo: Parábola, 2004.

MARINHO, M. A escrita nas práticas de letramento acadêmico. Revista Brasileira de Linguística Aplicada, Belo Horizonte, v. 10, n. 2, p. 363-386, 2010.

McLEOD, S.; MARGO. S. Academic Writing: Interdisciplinary Perspectives on communication Across the Curriculum. Sage Publications, Newbury Park, CA, 1992. Publicação online em 2000. 
Disponível em http://aw.colostate.edu/books/ Acesso em novembro de 2013.

MOTTA-ROTH, D. Rhetorical Features and Disciplinary Cultures: A Genre-Based Study of Academic Book Reviews in linguistics, Chemistry, and Economics. 1995. 356f. Tese (Doutorado em Linguística Aplicada) - Pós-Graduação e Letras-Inglês, Universidade Federal de Santa Catarina, Florianópolis, 1995.

MOTTA-ROTH, D.; HENDGES, G. R. Produção textual na universidade. São Paulo: Parábola Editorial, 2010.

PASQUOTTE-VIEIRA, Eliane A. Letramentos Acadêmicos (re)significações e (re)posicionamentos de sujeitos discursivos. 2014. 262f. Tese (Doutorado em Educação) - Instituto de Estudos da Linguagem, Universidade Estadual de Campinas, Campinas, 2014.

SILVA, E. M. da. Resumo acadêmico. In: (Org). Professora, como é que se faz? Campina Grande: Bagagem, 2012. 43-64.

STREET, B. Hidden Features of Academic Paper Writing. Working Papers in Educational Linguistics, UPenn Vol. 24, no 1, 1-17, 2009.

SWALES, J. Repensando gêneros: uma nova abordagem ao conceito de comunidade discursiva. In: BEZERRA, B.; BIASI-RODRIGUES, B.; CAVALCANTE, M. (Orgs.). Gêneros e sequências textuais. Recife: Edupe, 2009 [1992]. 197-220.

Genre Analysis: English in academic and research settings. Cambridge: University Press, 1990.

WAZLAWICK, R. S. Metodologia de Pesquisa para Ciência da Computação. Rio de Janeiro: Elsevier Editora, 2009.

XAVIER, A. C. Como fazer e apresentar trabalhos científicos em eventos acadêmicos. Recife: RESPEL, 2010. 